\title{
Self Assembly of Cyanine Dye on Clay Nanoparticles
}

\author{
Andrew Dixon, Clint Duncan, and Hussein Samha* \\ Department of Physical Science \\ Southern Utah University \\ Cedar City, Utah 84720 USA
}

Received: January 10, 2005 Accepted: February 18, 2005

\begin{abstract}
The effect of Ca-montmorillonite (clay) on the aggregation behavior of the cyanine dye, 1,1'diethyl-2,2'-cyanine iodide (PIC), in aqueous solutions has been investigated using UV-vis spectroscopy. The absorbance of the monomeric dye in aqueous solutions is compared with the absorbance of the aggregates formed after adding the clay. The appearance of a sharp "redshifted" band centered at $574 \mathrm{~nm}$, after the addition of clay to the aqueous solutions of the dye, indicates the formation J-aggregates on the charged surfaces of the clay particles. The spontaneous and quantitative transformation of monomers into J-aggregates was controlled by the concentration of the clay in the solution. Successive addition of clay to the dye solution causes an increase in the absorbance intensity of the J-band and consequently, a decrease in the absorbance intensity of the monomer. These changes occur linearly which suggests that the dye monomers are quantitatively being converted to J-aggregates.
\end{abstract}

\section{INTRODUCTION}

In recent years the fabrication of functional supramolecular structures utilizing inorganic and organic frameworks has become of great interest both from the scientific and practical standpoints [1]. Cyanine dyes (Figure 1) in particular have been of interest in this area of research for both their unusual optical properties and high fluorescent quantum yield of their aggregates. Strongly absorbing in the visible region, cyanine dyes are highly fluorescent in monomers and aggregates both in solution and organized media. The two types of aggregates that are known for cyanine dyes are "H-aggregate" recognized by their blue shifted broad absorption band and "J-aggregate" that exhibit a sharp red shifted absorbance with respect to the monomer absorption. The ease of formation of aggregates in conjunction with their potential applications in optical devices, photosensitizers, and fluorescent probes for bio-membrane fluidity made cyanine dyes particularly interesting [2-4]. The Jaggregates that have been investigated for the past few years can be considered as a model system for more complex excitonic systems, like light harvesting pigment molecules in natural photosynthetic antenna systems [5]. Several methods have been developed for inducing aggregate formation in aqueous solutions; such as raising the dye concentration in solution, using highly concentrated electrolytic solutions, and by<smiles>CCN1/C(=C/c2ccc3ccccc3[n+]2CC)C=Cc2ccccc21</smiles>

Figure 1. Structure of 1,1'-diethyl-2,2'cyanine dye 
adding certain polyelectrolyes [6-8]. In this paper we report the tendency of PIC to form J-aggregates on the surfaces of montmorillonite clay particles in aqueous dispersions. Evidently, a quantitative transformation of the dye monomers into $\mathrm{J}$ aggregates is observed from the absorption spectra of the dye. We also report the exchange capacity of the montmorillonite clay using PIC and evaluate whether our results were able to fall in the range of the exchange capacity from different studies that have used the same clay with different ionic species.

\section{EXPERIMENTAL SECTION}

A $19.36 \mathrm{mM}$ aqueous solution of PIC was prepared as a stock solution and a more diluted solution of a concentration of $1.936 \times 10^{-2} \mathrm{mM}$ was prepared from the stock solution by dilution as needed. An aqueous suspension of montmorillonite clay, calcium salt, of $0.0996 \mathrm{~g}$ in $40 \mathrm{~mL}(2.49$ $\mathrm{mg} / \mathrm{mL}$ ) was prepared in de-ionized water then bath sonicated (BRANSON 8200) for 15 minutes. Before use, the clay suspension was stirred using a magnetic bar and a magnetic stirrer for at least 30 minutes and continued stirring through out the course of the measurements. A spectrophotometer from Ocean Optics (model CHEM 2000 UV-VIS) was used to measure the absorbance of the dye in solution. Using a micropipette, the clay suspension was added in increments of 1.0 $\mu \mathrm{L}$ to a $2.0 \mathrm{~mL}\left(1.94 \times 10^{-2} \mathrm{mM}\right)$ of the dye solution in a cuvette. The solution was well mixed by shaking the cuvette and the absorbance of the dye was recorded immediately. The incremental additions continued until no further change in the absorbance of the dye was noticed.

\section{RESULTS AND DISCUSSION}

Figure 2 shows the absorbance of the dye monomer in aqueous solution before addition of the clay. The spectrum indicates the absorbance of the monomer (broad band) at $524 \mathrm{~nm}$.

After the addition of $1.0 \mu \mathrm{L}$ of the clay suspension to the $2.0 \mathrm{~mL}$ of the dye solution in the cuvette, a small but significant shoulder peak appears at $574 \mathrm{~nm}$ in the absorption spectrum of the dye (Figure 3 ). This red-shifted peak corresponds to the absorption of the $\mathrm{J}$-aggregate of the dye.

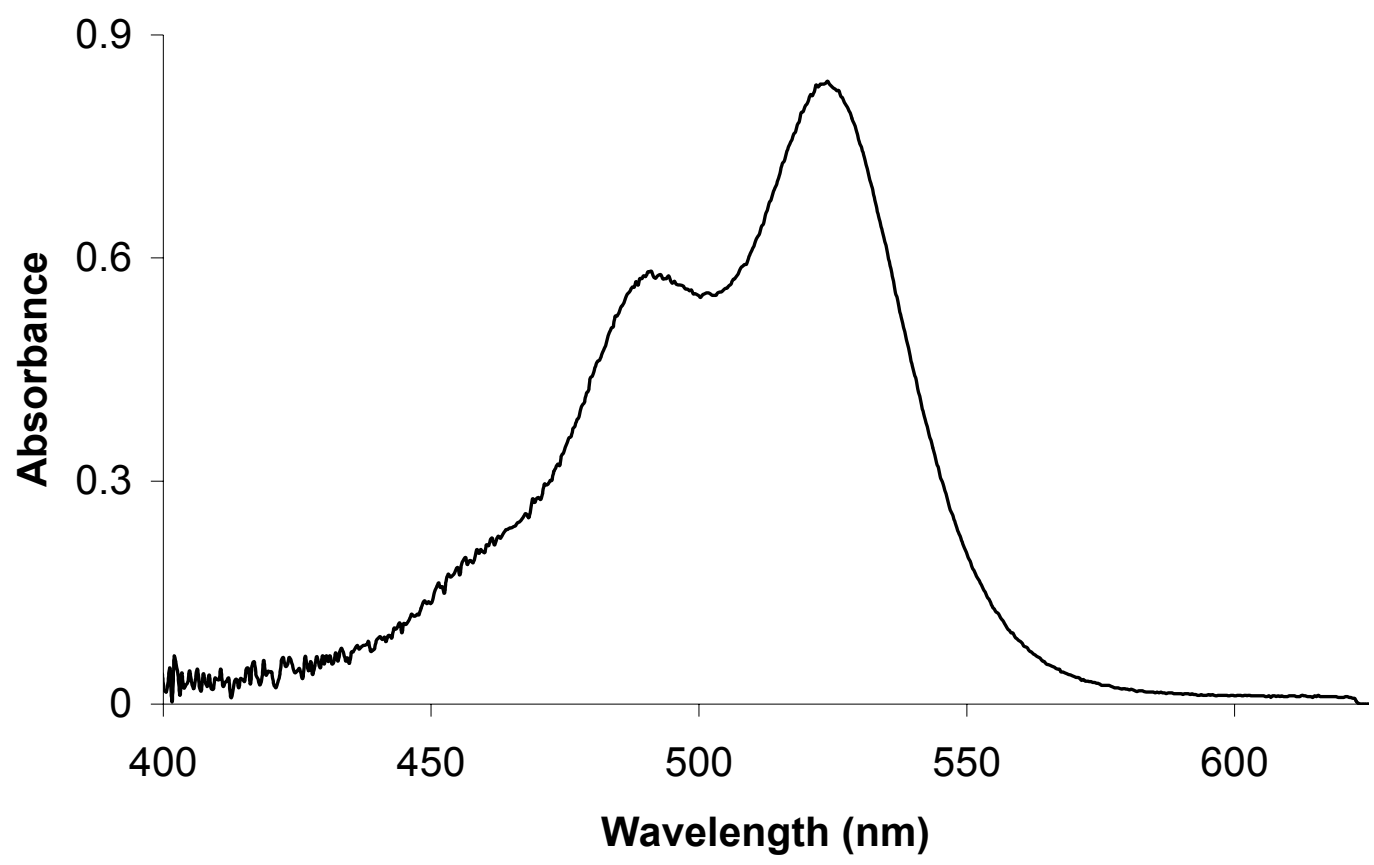

Figure 2. Absorbance of PIC $\left(3.87 \times 10^{-5} \mathrm{mM}\right)$. 


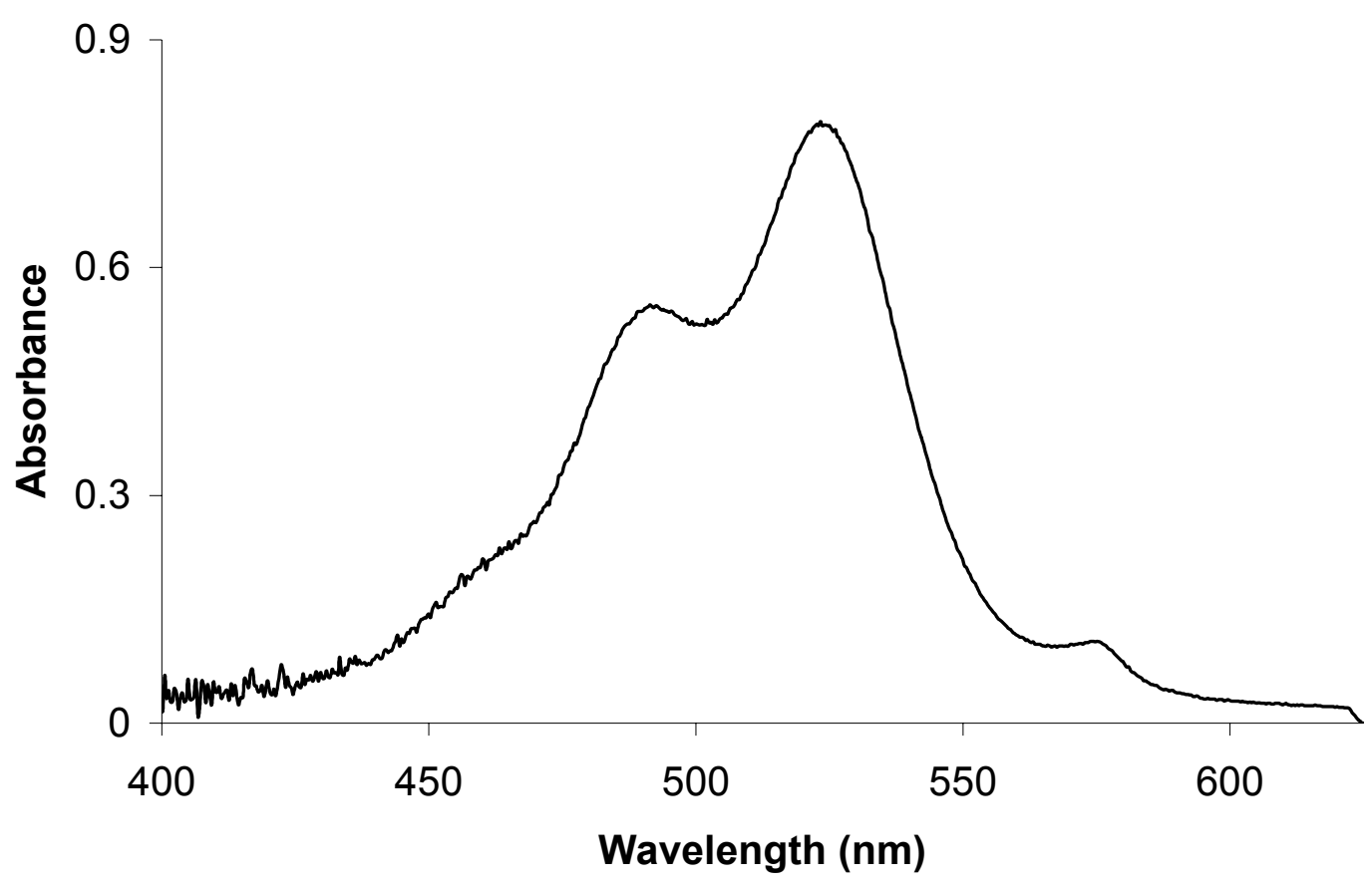

Figure 3. Absorbance of PIC after the addition of $1.0 \mu \mathrm{L}$ clay solution.

Thus, the formation of the aggregates was apparent immediately $(\mathrm{J}-$ band became evident after first addition of clay). Addition of clay suspension in the increments of $1.0 \mu \mathrm{L}$ was continued and the absorbance of the mixture was recorded after each addition. The absorbance of the dye continued to change as more clay was added to the cuvette until it reached a point where no significant change in the absorbance was noticeable. During the addition of the clay suspension, the absorbance of the dye monomers continued to decrease while J-band, which corresponds to the absorbance of the $\mathrm{J}$ aggregates, continued to grow as shown in Figure 4.

The data of the absorbance at the center of the J-band $(574 \mathrm{~nm})$ and the calculated concentration of clay in the dye solution were used to plot the absorption isotherm (Figure 5) which illustrates the linear relationship between the aggregates formed and the clay concentration. The isotherm also shows that the saturation level of clay has been achieved after about $12 \mu \mathrm{L}$ ( $772 \mathrm{mg}$ clay/ mmol dye) of the clay had been added to the dye solution. This result represents the average of three separate trials of the experiment. At this point, there was no further change in the absorbance intensity of the monomers or the aggregates occurred, which indicates that the saturation point was reached where every accessible exchanging site on clay platelets has been occupied by a dye molecule. At this concentration ratio, the absorbance of the aggregates starts leveling off indicating the conversion of the monomeric dye into $\mathrm{J}$ aggregates. A closer look at the absorbance spectrum at the calculated stoichiometric ratio above shows clearly that there is almost no monomer remaining in the solution (monomer absorbs at $523 \mathrm{~nm}$ ). The appearance of only one isosbestic point in the UV-Vis spectra suggests that when an aqueous solution of PIC is treated with clay, the dye monomers are converted to $\mathrm{J}$ aggregates.

After $12 \mu \mathrm{L}$ of clay $\left(2.49 \times 10^{-3}\right.$ $\mathrm{mg} / \mu \mathrm{L})$ had been added to the $3.87 \times 10^{-5}$ mmol PIC solution $\left(2.0 \mathrm{~mL} \times 1.94 \times 10^{-5} \mathrm{M}\right)$ the clay platelets were saturated with the dye molecules at a concentration ratio of 1.3 $\mathrm{mmol}$ dye/g of clay. This ratio is the average of the three experiments that were 


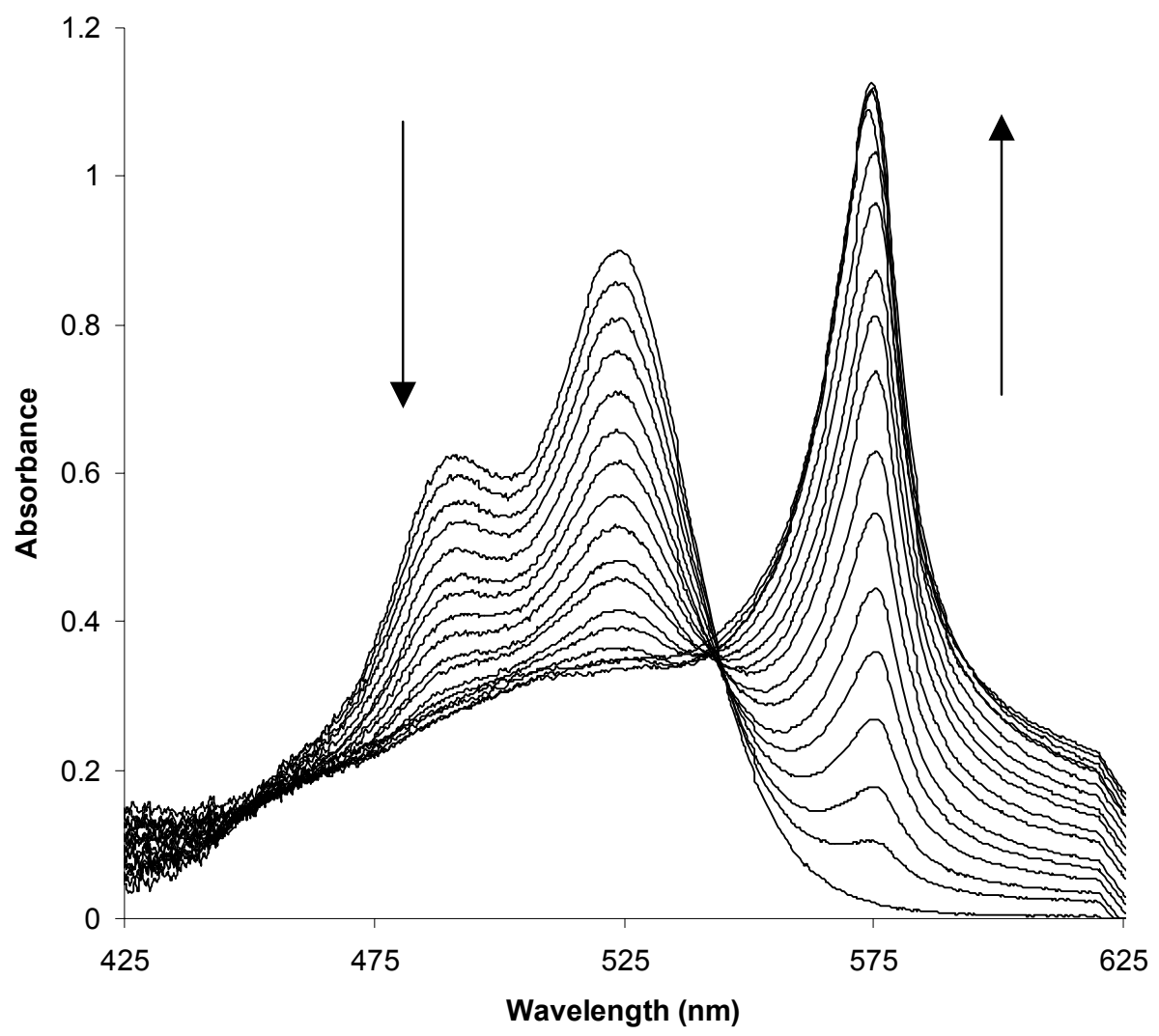

Figure 4. Change in the absorbance of PIC as a function of clay added. (Clay was added in $1.0 \mu \mathrm{L}$ increments to a total volume of $12 \mu \mathrm{L}$ ).

performed multiple times using the same technique. The calculated average marginal error was less than $6 \%$. After review of two references about the exchange capacity of the montmorillonite, we have found that our result of $1.3 \mathrm{mmol}$ dye/g clay, fits comfortably in the range listed in both references. Using metal ions, Sparks has listed the exchange capacity of montmorillonite at any where from 80-150 $\mathrm{cmol} / \mathrm{Kg}$ [9]. With the appropriate conversion, that puts our value at $130 \mathrm{cmol} /$ $\mathrm{Kg}$. In another experiment published by the Journal of Materials Chemistry by Fan et al [10], the group noted the exchange capacity in one experiment at $122 \mathrm{mmol} / 100 \mathrm{~g}$ and in another at $96.5 \mathrm{mmol} / 100 \mathrm{~g}$ [10]. Again, our calculated average exchange capacity (130 $\mathrm{mmol} / 100 \mathrm{~g}$ ) comes in perfect agreement with the reported results.

The focus of the research was to investigate the behavior of cyanine dyes in solutions containing particles that have charged surfaces such as clay. The results obtained suggest that PIC molecules can self assemble themselves on the surface of clay and form $\mathrm{J}$ aggregates by a cation exchange mechanism. The ease by which J-aggregates are obtained on clay makes this technique particularly interesting. Knowing the nature of clay and the dependence of its surface charge intensity on the experimental conditions, we found it worthwhile to point out the high agreement between the experimental exchange capacity we determined and other exchange capacities reported in the literature. This exchange capacity can be used as one evidence to reach the saturation level of the clay.

\section{CONCLUSION AND FUTURE RESEARCH}

Stable J-aggregates of positively charged PIC were self assembled on the negatively charged surface of clay platelets. The adsorption isotherm of the aggregates 


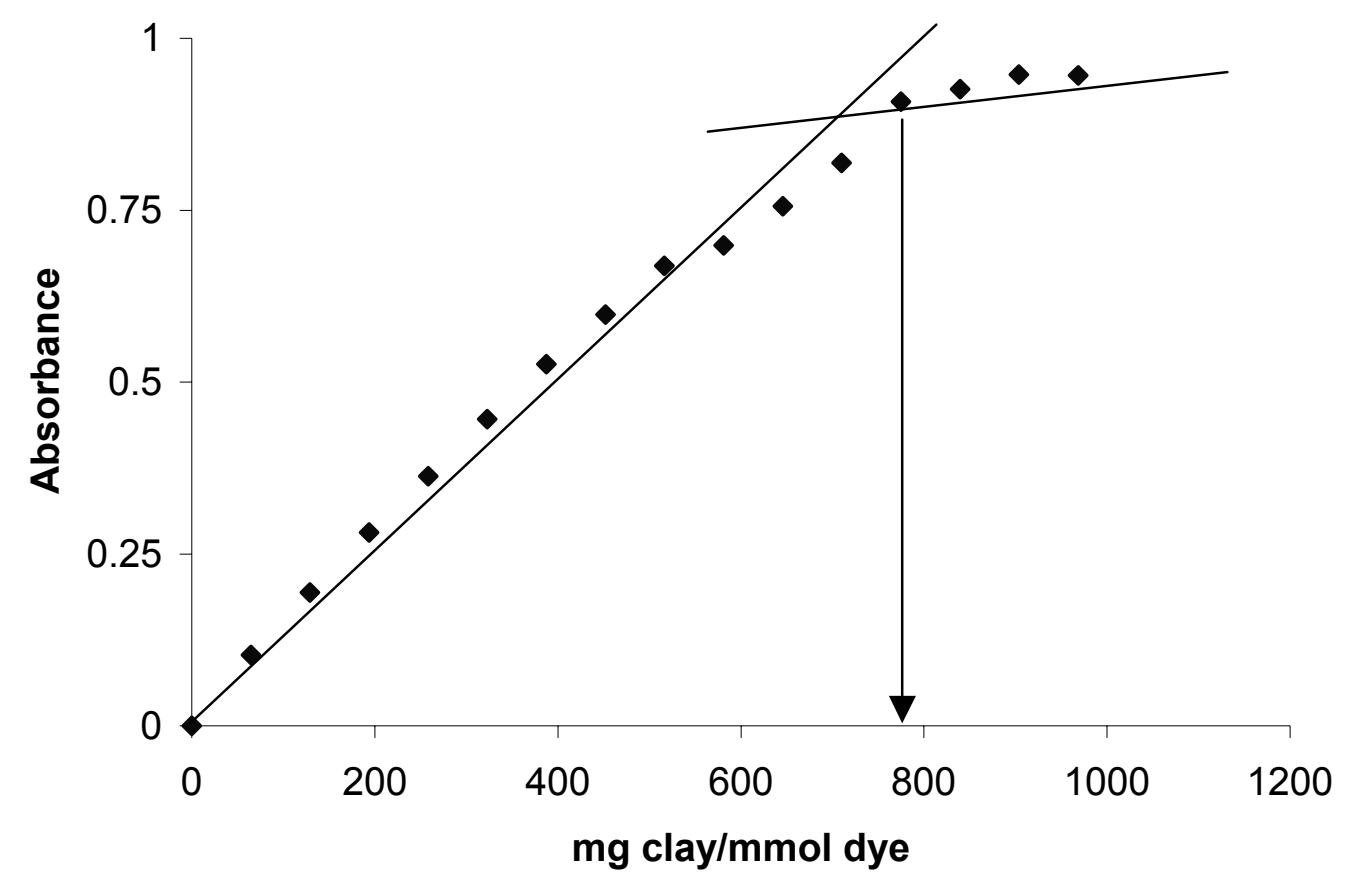

Figure 5. Absorbance intensity of $\mathrm{J}$-band as a function of clay added.

was used to calculate an exchange capacity of $130 \mathrm{mmol} / 100 \mathrm{~g}$ for the clay used. The ease by which J-aggregates can be obtained on clay nanoparticles and their high stability even in solution has motivated us to study the kinetics of the electron transfer in the aggregates. In the future, our research effort will be focused on developing a two-component system of aggregates (photosensitizer) and a suitable electron acceptor using clay particles as micro substrates.

\section{REFERENCES}

1. N. Miyamoto, K. Kuroda, and M. Ogawa, Journal of Materials Chemistry, 2004, 14,165.

2. A.S.R. Koti and N. Periasany, Journal of Materials Chemistry, 2002, 12, 2312.

3. W. West and P.B. Gilman, Theory of the Photographic Process, ed, T.H. James, Macmillan, New York, 1977.

4. P.F. Fakey, D.E. Koppel, L.S. Barak, D.E. Wolf, E.L. Elson, and W.W. Webb, Science, 1977, 195, 305.
5. V. Sundstrom and R. VanGrondelle, Journal of Optical Chemistry B7, 1595 (1990).

6. R. Pasternack, C. Fleming, S. Herring, Biophysical Journal, July 2000, pp. 551552, Vol. 79, No. 1.

7. Horng, M.L., and E.L. Quitevis, 1993, Excited-state Dynamics of Polymerbound J-aggregates, J. Physical Chemistry, 97: 12408-12415.

8. W. Tillman, and H. Samha, American Journal of Undergraduate Research, 2004, 3 (3), 1.

9. Sparks, D.L. 1995, Sorption phenomena in soil: Pages 99-139 in Environmental Soil Chemistry. San Diego, CA: Academic Press.

10. Lei Song, Yuan Hu, Shaofen Wang, Zuyao Chen, and Weicheng Fan, Journal of Materials Chemistry, 2002, 12, 3152-3155. 
